\title{
Automated control procedures and first results from the temporary seismic monitoring of the 2012 Emilia sequence
}

\author{
Simone Marzorati ${ }^{1}$, Simona Carannante ${ }^{1,}{ }^{\star}$, Marco Cattaneo $^{1}$, Ezio D'Alema ${ }^{1}$, Massimo Frapiccini ${ }^{1}$, \\ Chiara Ladina ${ }^{1}$, Giancarlo Monachesi ${ }^{1}$, Daniele Spallarossa ${ }^{2}$
}

\author{
${ }^{1}$ Istituto Nazionale di Geofisica e Vulcanologia, Centro Nazionale Terremoti, Ancona, Italy \\ ${ }^{2}$ Università di Genova, Dipartimento per lo Studio del Territorio e delle sue Risorse, Genova, Italy
}

\author{
Article history \\ Received July 19, 2012; accepted August 14, 2012. \\ Subject classification: \\ Data quality control, Emilia sequence 2012, Automatic earthquake location, 3D tomographic model.
}

\section{Introduction}

After moderate to strong earthquakes in Italy or in the surrounding areas, the Istituto Nazionale di Geofisica e Vulcanologia (INGV; National Institute for Geophysics and Volcanology) activates a temporary seismic network infrastructure. This is devoted to integration with the Italian National Seismic Network (RSN) [Delladio 2011] in the epicentral area, thus improving the localization of the aftershocks distribution after a mainshock. This infrastructure is composed of a stand-alone, locally recording part (Re.Mo.) [Moretti et al. 2010] and a real-time telemetered part (Re.Mo.Tel.) [Abruzzese et al. 2011a, 2011b] that can stream data to the acquisition centers in Rome and Grottaminarda.

After the May 20, 2012, M 5.9 earthquake in the Emilia region (northern Italy), the temporary network was deployed in the epicentral area; in particular, 10 telemetered and 12 stand-alone stations were installed [Moretti et al. 2012, this volume].

Using the dedicated connection between the acquisition center in Rome and the Ancona acquisition sub-center [Cattaneo et al. 2011], the signals of the real-time telemetered stations were acquired also in this sub-center. These were used for preliminary quality control, by adopting the standard procedures in use here (see next paragraph, and Monachesi et al. [2011]). The main purpose of the present study is a first report on this quality check, which should be taken into account for the correct use of these data. In a second step, the data recorded by the real-time temporary network were integrated with data from the 12 stand-alone stations and from 27 stations of the RSN (up to a distance of ca. $120 \mathrm{~km}$ ). The use of automatic detectors and phase pickers allowed the recognition and locating of more than 2000 earthquakes in the first 12 days of the sequence. These data were used for preliminary determination of a three-dimensional (3-D) propagation model, which was used, in turn, for a re-location of the events. This led to a first reconstruction of the seismogenic structures that were activated during the first part of the sequence.

\section{Quality control of the data}

The continuous stream of data from the telemetered stations is subjected to control procedures that are mainly devoted to the monitoring of the data availability and the quality of the seismic signals.

Data availability is checked by means of scripts contained in the PASSCAL package (http:/ / www.passcal.nmt. edu/content/software-resources), the outputs of which are organized to allow a graphical representation, which is useful for quick recovery of possible critical points. Indeed, the real-time stations use different transmission channels: satellite, and ultrahigh frequency + satellite [Abruzzese et al. 2011a, 2011b], or Universal Mobile Telecommunications System [Govoni et al. 2012]. A comparison between the time occurrence of data gaps during the day at the different stations allows restriction of the possible causes of data loss, and thus to drive the intervention of the field teams in case of critical data-flow interruptions. For example, Universal Mobile Telecommunications System station T0822 showed occasional data losses during the day, while the night transmission was perfect, which suggested a saturation of the phone cells in case of higher usage; a change of the phone operator completely solved the problem.

On the other hand, the quality of seismic signals is monitored by means of the PQLX software [McNamara and Buland 2004], which is aimed at monitoring the noise levels in the signals. For each channel of each station, it is possible to compute power spectral densities (PSDs), using one-hour time windows with an overlap of $50 \%$, which are the basis for the evaluation of probability density functions (PDFs). The comparisons of the PDFs between different 

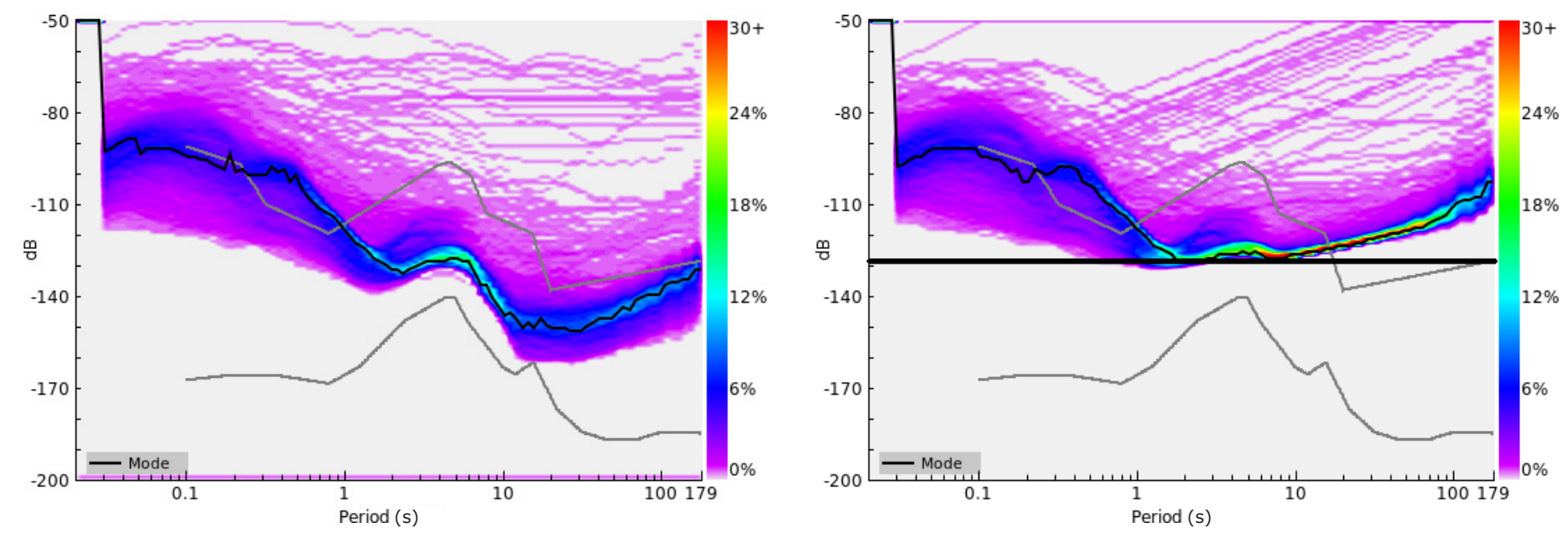

Figure 1. Comparison between the PDF statistics at station T0800. Left: Velocimetric broad-band sensor; Right: Strong-motion accelerometer. Thick black line, theoretical resolution limit $(-128 \mathrm{db})$ of the coupling sensor-digitizer. Both panels: Upper gray curve, reference New High-Noise Model; lower gray curve, New Low-Noise Model [Peterson 1993].

stations, and with respect to reference terms, like the New High-Noise Model (NHNM) [Peterson 1993], allow possible imperfections in the sensor installation to be quickly recognized (e.g., leveling, coupling). It should be remembered that in these cases, the installations are often performed in relatively critical situations. Fortunately, with this installation to date, the sensors of the real-time stations have not shown any particular critical situations, apart from a leveling loss at T0800, which was solved at the first station control in the field.

The availability of PDF statistics also allows the resolution capability of the stations to be recognized; this resolution is determined from one side by the instrumental characteristics, and from the other side by the environmental noise. In this area, the first instrumental aspect appears to be negligible compared to the environmental aspect, at least at short periods. Figure 1 shows the comparison between the PDF statistics at station T0800, as measured from a velocimetric broad-band sensor (Nanometrics Trillium T120 Compact; Figure 1, left side) and a strong-motion accelerometer (Kinemetrics Episensor; full scale 2g; Figure 1, right side). In the accelerometer plot, the theoretical resolution limit of the coupling sensor-digitizer is also reported (Figure 1, thick black line). In this case, it is evident that the resolution limit does not influence the acquisition, because the spectra of the recorded signals are above this limit. In particular, in the short period part of the spectrum (below $1 \mathrm{~s}$ ), the PDF distributions are in good agreement, which confirms that the accelerometer can correctly record the ground motion related to weak events that are detected by the velocimeter. This is common to all of the stations installed in the epicentral area, and it is not surprising: the mean noise curves are in agreement with results of previous analyses in the Po Plain. Marzorati and Bindi [2006] showed that the noise levels often reach the limit of the Peterson's NHNM. Also, the observed variations in the noise levels between day and night, which suggest a mainly anthropic source, are similar to values already reported [Marzorati and Bindi 2006], and are between $5 \mathrm{~dB}$ and $15 \mathrm{~dB}$ [Marzorati et al. 2012].

\section{Quality control through data use}

One of the best controls of the performances of the infrastructure of a seismic network that is composed of a locally recording part and a real-time telemetered part is to use its data to locate earthquakes. For this purpose, to obtain a quick but reliable response on the effectiveness of the integration between the temporary and permanent networks operating in the area, we adopted a semi-automated approach.

The first step was the construction of an integrated dataset: we selected the stations of the national network located at distances of less than $120 \mathrm{~km}$ from the barycenter of the sequence. Their continuous recordings were merged with the recordings of the temporary network. In this first analysis, the time span from 20 to 31 May, 2012, was considered.

The continuous recordings were searched for events, using a simple short-time average (STA)/long-time average (LTA) algorithm on band-pass filtered signals between $2 \mathrm{~Hz}$ and $15 \mathrm{~Hz}$, and a coincidence criterion. For this preliminary analysis, relatively restrictive criteria were adopted (e.g., signal-to-noise ratio threshold of 10 , coincidence of 4 stations within $20 \mathrm{~s}$ ): in this way, 2365 time windows were selected, each of $65 \mathrm{~s}$ long.

These time windows were used for an automatic picking procedure [Spallarossa et al. 2011]. The proposed automatic phase picker includes envelope calculation, band-pass filtering, an Akaike information criterion (AIC) detector for both P-arrivals and S-arrivals, checking for impulsive arrivals, evaluation of expected $S$ onset on the basis of a preliminary location derived from the P-arrival times, and quality assessment. The advantage of this technique is that it provides consistent arrival-time picks for $\mathrm{P}$-waves and S-waves, and provides reliable automatic earthquake locations. More insight into the 

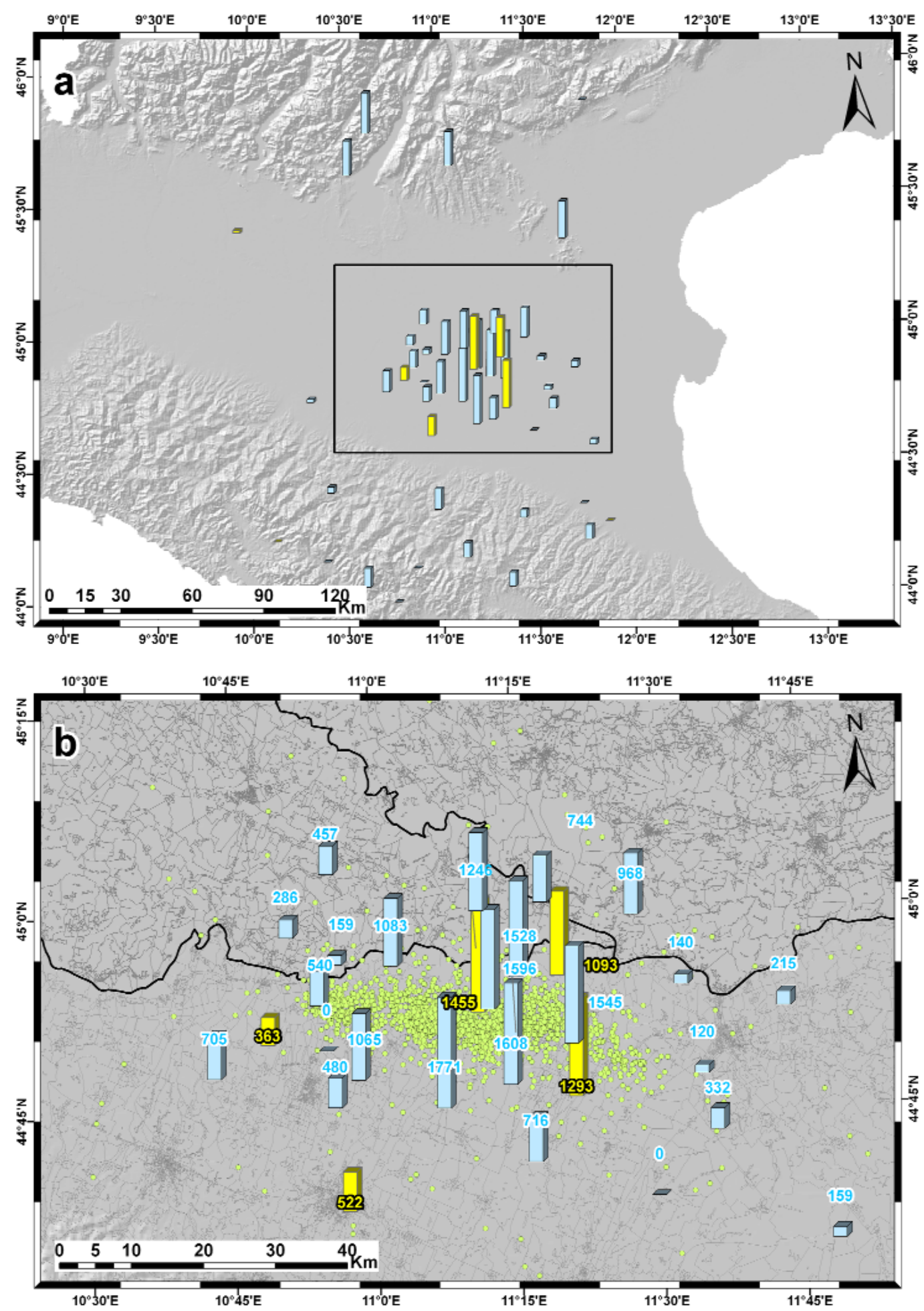

Figure 2. Number of automatic P pickings for each station. (a) whole area; (b) zoom on the epicentral area, as shown by the black rectangle in (a). The color of the bars represents the two kinds of sensors: velocimeter, blue; accelerometer, yellow.

adopted procedure can be found in Spallarossa et al. [2012].

The picker furnishes arrival times of P-phases and (if recognized) S-phases, and an estimate of uncertainty, classified in the standard hypo-family quality class $(0$, most reliable; 3 , less reliable), based on an analysis of the signal-to-noise ratio.

The automatic picker recognized 30467 P-phases and 22689 S-phases; these phases allowed the localization of 2300 earthquakes. In Figure 2a, the number of automatic pickings for each station is reported on the map. It is worth not- ing that the effectiveness of stations in furnishing a high number of pickings is mainly related to the mean distance with respect to the epicenter distributions, while the kind of sensor, e.g., velocimeter (blue bar) or accelerometer (yellow bar), does not appear to influence the detection. As already stated, this is due to the relatively high mean noise level below $1 \mathrm{~s}$ that in this area hides the loss of resolution of the strong-motion sensors. The strong asymmetry in the picking numbers between Alpine stations (Figure 2a, north- 

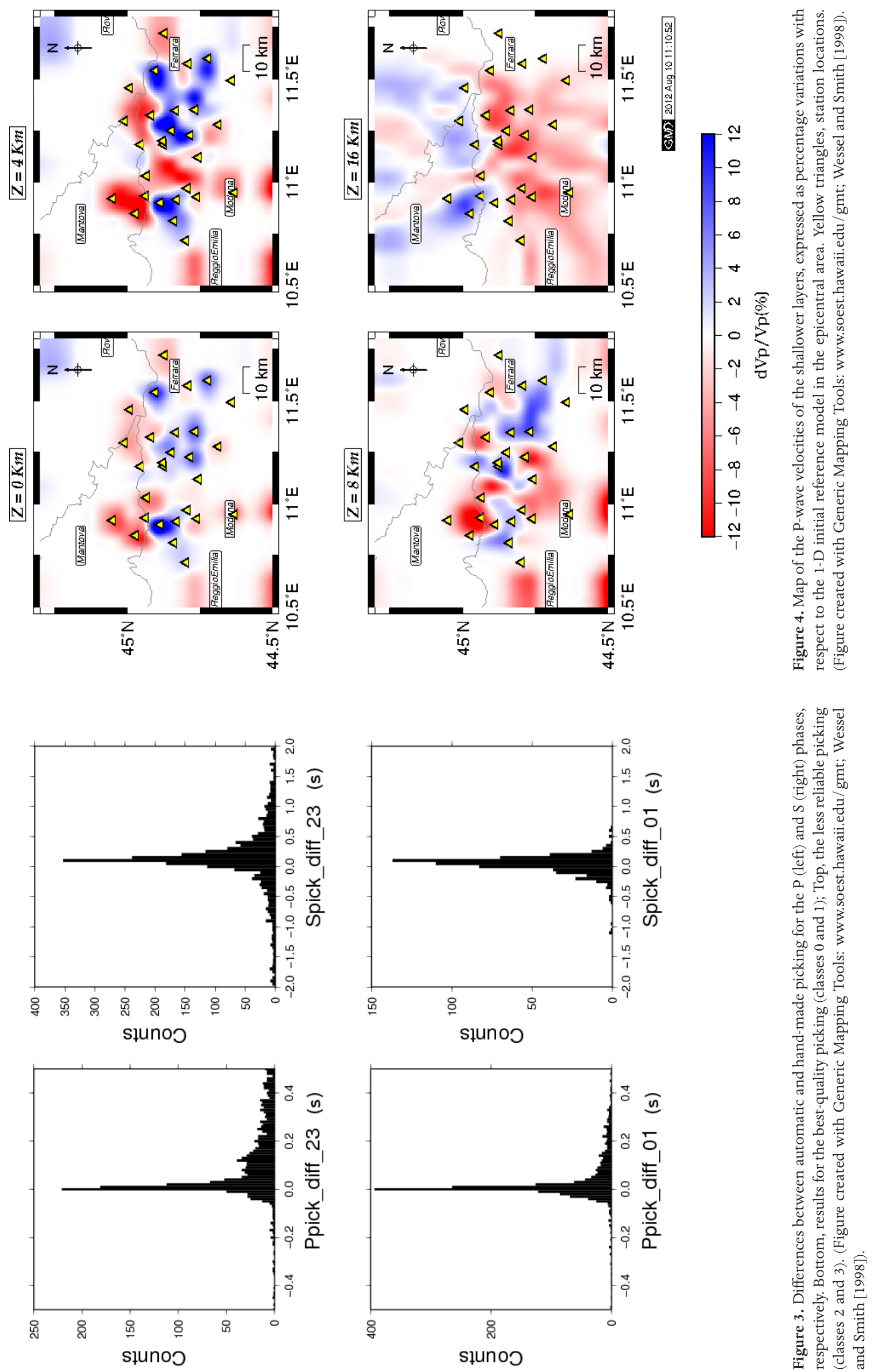

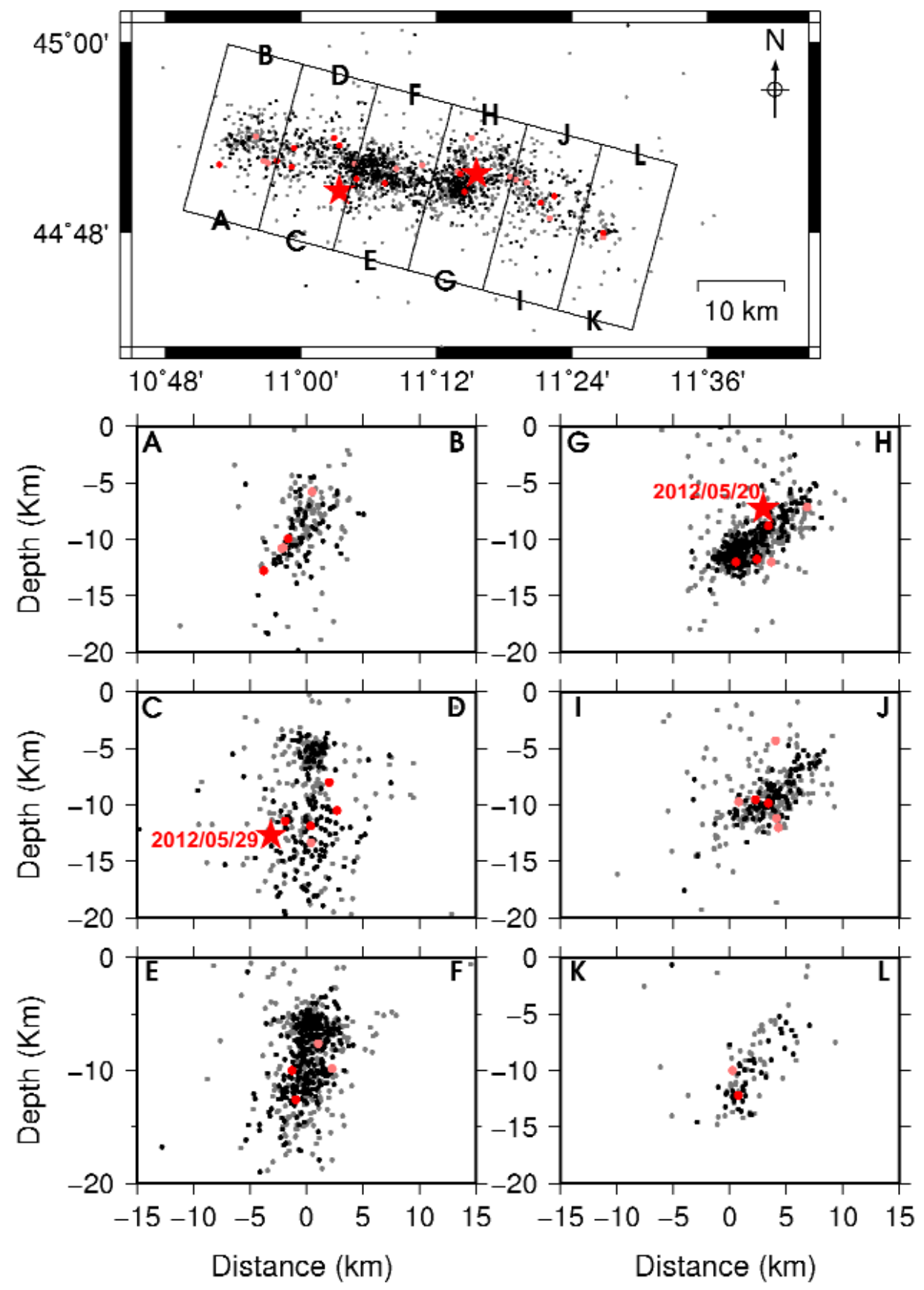

Figure 5. Relocated events in the 3-D structure. Full black color, the most reliable locations (at least 20 phases with nonzero weight, final residual rms $<0.2 \mathrm{~s}$ ). Gray tones, remaining locations, with less drastic constraints (at least 8 phases, rms $<0.4 \mathrm{~s}$ ). Red points, the most reliable events with local magnitudes $>4.0$ (light red points, those with less drastic constraints). Stars, the two mainshocks. (Figure created with Generic Mapping Tools: www.soest.hawaii.edu/gmt; Wessel and Smith [1998]).

ern part) and Apennine stations (Figure 2a, southern part) is also noticeable, due to a higher signal-to-noise ratio.

To control and tune the picker parameters, about 200 events were also picked by an expert analyst, and used for a comparison. In spite of the previously noted high levels of ambient noise, the results are very encouraging (Figure 3): the difference between the automatic and the hand-made pickings is quite narrow, at around the zero, with $77.7 \%$ of data below $0.1 \mathrm{~s}$ for the best-quality picking (class 0 and 1 ) for P-waves, and $84.8 \%$ below $0.2 \mathrm{~s}$ for $\mathrm{S}$-waves. The less reliable picking (classes 2 and 3 ) show differences that are obviously higher; nevertheless, $74.1 \%$ of the differences are below $0.4 \mathrm{~s}$ for P-waves, and $81.3 \%$ below $0.8 \mathrm{~s}$ for $\mathrm{S}$-waves. The distribution of differences shows an asymmetry towards positive values (i.e., the automatic picking is delayed with respect to the hand-made one). This asymmetry is limited to the tail of the distribution for P-phases, and it is more enhanced for the low-quality pickings: indeed, for classes 0 and 1 the mean value is $0.016 \mathrm{~s}$ if we take into account just the differences below $0.2 \mathrm{~s}$, and it increases to $0.050 \mathrm{~s}$ on the whole dataset. For classes 2 and 3, the mean values are $0.040 \mathrm{~s}$ (below $0.2 \mathrm{~s}$ ) and $0.161 \mathrm{~s}$ (whole dataset), respectively. For S-phases, the mean values are higher, mainly due to the less reliable pickings; indeed, for classes 0 and 1 , the mean values are 
$0.048 \mathrm{~s}$ (below $0.2 \mathrm{~s}$ ) and $0.037 \mathrm{~s}$ (whole dataset), while for classes 2 and 3 we obtain $0.072 \mathrm{~s}$ (below $0.2 \mathrm{~s}$ ) and $0.125 \mathrm{~s}$ (whole dataset), respectively. In our opinion, these very small asymmetries confirm the good performances of the automatic picker, and should lead to a reduced impact on the location procedure.

To take into account the strong heterogeneity of the propagation medium, both in the epicentral zone and in the surrounding areas, a preliminary 3-D model was evaluated using a joint inversion for earthquake locations and propagation anomalies, through the Simulps14 code [Thurber 1983, 1993]. For this, the best located events of the dataset were selected on the basis of the number of used phases (30), of the maximum azimuthal gap $\left(150^{\circ}\right)$ and of the final $\mathrm{rms}$ of the residuals $(0.3 \mathrm{~s})$ : in this way, 499 earthquakes were selected.

The joint inversion led to the reconstruction of 3-D Pwave and $\mathrm{S}$-wave propagation models that are relatively detailed in the epicentral area. The main characteristics of the P-wave velocity miodel are shown in Figure 4. Although a complete discussion of this model is beyond the scope of this preliminary study, it is worth noting the good correlation between the high-velocity anomalies of the shallower layers and the well-known structural highs buried beneath the eastern Po Plain [Bigi et al. 1992]. For the deeper layer (Figure 4, $Z=16 \mathrm{~km}$ ), the main feature is the evident mean velocity of the Alpine crust (propagations towards the North), with respect to the Apennine one (towards the South). The 3-D P-wave and S-wave propagation models were used to locate all of the events of the dataset; in Figure 5 , a selection of the locations is plotted, as map and crosssections perpendicular to the strike of the mainshock, as inferred by the time-domain moment tensor mechanism computed by the INGV (http:/ / cnt.rm.ingv.it/tdmt.html). The most reliable locations (i.e., at least 20 phases with nonzero weight, final residual $\mathrm{rms}<0.2 \mathrm{~s}$ ) are reported in full color (908 events). For the remaining ones that are plotted in gray tones in Figure 5, less drastic constraints were adopted (i.e., at least 8 phases, $\mathrm{rms}<0.4 \mathrm{~s}$ ), with 1104 events selected, for a gross total of 2012 reported events $(87.5 \%$ of the initial events). The events with local magnitudes larger than 4.0 are plotted in red in Figure 5, while the stars demonstrate the two mainshocks (2012/05/20,2h03', $\mathrm{M}_{\mathrm{L}} 5.9$, and $2012 / 05 / 29,7 h 00 ', M_{L} 5.8$ ). From the map view, the misalignment of the eastern sector of the sequence is quite evident, where the first mainshock occurred, and the western sector, which was mainly active in the last part of the period analyzed. The easternmost cross-sections (Figure 5, G-H, I-J and K-L) show clear deepening of the hypocenters towards the south at an angle of about $45^{\circ}$, which is comparable with one of the focal planes obtained by the time-domain moment tensor mechanism. The central sections show a more complex distribution, which might be related to the superposition of different structures, or maybe to nonpla- nar structures. Only the westernmost section appears to depict a simple south-dipping plane again.

A more complete analysis of the 3-D propagation model and of its effects on the location procedure will be the object of a more detailed study, which is already in progress, and which also uses a more complete dataset.

\section{References}

Abruzzese, L., G. De Luca, M. Cattaneo, G. Cecere, V. Cardinale, A. Castagnozzi, C. D'Ambrosio, A. Delladio, M. De Martin, L. Falco, D. Franceschi, A. Govoni, A. Mammolo, F. Migliari, F. Minichiello, M. Moretti, M. Moschillo, M. Pignone, G. Selvaggi and L. Zarrilli (2011a). La rete sismica mobile in telemetria satellitare (Re.Mo.Tel.), Rapporti Tecnici INGV, 177, ISSN 20397941 (in Italian).

Abruzzese, L., G. Cecere, G. De Luca and L. Zarrilli (2011b). Re.Mo.Tel.: l'esperienza durante l'emergenza "L'Aquila 2009", In: M. Cattaneo and M. Moretti (eds.), Monitoraggio sismico del territorio nazionale: stato dell'arte e sviluppo delle reti di monitoraggio sismico, Miscellanea INGV, 10, 55-56 ISSN 2039-6651 (in Italian).

Bigi, G., D. Cosentino, M. Parotto, R. Sartori and P. Scandone (1992). Structural model of Italy. Scala 1:500,000. C.N.R., Progetto Finalizzato Geodinamica, Sottoprogetto: Modello strutturale tridimensionale, Quaderni della Ricerca Scientifica, 114, 3.

Cattaneo, M., E. D'Alema, M. Frapiccini, S. Marzorati and G. Monachesi (2011). Acquisizione presso la sede di Ancona, In: M. Cattaneo and M. Moretti (eds.), Monitoraggio sismico del territorio nazionale: stato dell'arte e sviluppo delle reti di monitoraggio sismico, Miscellanea INGV, 10, 91-93, ISSN 2039-6651 (in Italian).

Delladio, A. (2011). Monitoraggio sismico del territorio nazionale, In: M. Cattaneo and M. Moretti (eds.), Monitoraggio sismico del territorio nazionale: stato dell'arte e sviluppo delle reti di monitoraggio sismico, Miscellanea INGV, 10, 11-18, ISSN 2039-6651 (in Italian).

Govoni, A., G. Monachesi, M. Cattaneo, M. Moretti, A. Delladio and M. Frapiccini (2012). La sequenza sismica del 2010 nelle province di Macerata e Fermo e la sperimentazione della trasmissione dei dati in tempo reale via UMTS, Quaderni di Geofisica, 102, ISSN 1590-2595 (in Italian).

Marzorati, S., and D. Bindi (2006). Ambient noise levels in north central Italy, Geochem. Geophys. Geosyst., 7, Q09010; doi:10.1029/2006GC001256.

Marzorati, S., S. Carannante, M. Cattaneo, E. D'Alema, M. Frapiccini, C. Ladina and G. Monachesi (2012). Emergenza sismica 2012 in Emilia Romagna: attività sperimentali di supporto alla Rete Sismica Mobile INGV svolte dal personale della sede di Ancona, Rapporti Tecnici INGV, 236, ISSN 2039-7941 (in Italian). 
McNamara, D.E., and R.P. Buland (2004). Ambient noise levels in the continental United States, B. Seismol. Soc. Am., 94, 1517-1527.

Monachesi, G., M. Cattaneo, E. D'Alema, M. Frapiccini, S. Marzorati and M. Ferretti (2011). Sistemi di controllo in uso al centro di acquisizione della sede di Ancona, In: M. Cattaneo and M. Moretti (eds.), Monitoraggio sismico del territorio nazionale: stato dell'arte e sviluppo delle reti di monitoraggio sismico, Miscellanea INGV, 10, 103-107. ISSN 2039-6651 (in Italian).

Moretti, M., A. Govoni, G. Colasanti, M. Silvestri, E. Giandomenico, S. Silvestri, F. Criscuoli, L. Giovani, A. Basili, C. Chiarabba and A. Delladio (2010). La Rete Sismica Mobile del Centro Nazionale Terremoti. Rapporti Tecnici INGV, 137. ISSN 2039-7941 (in Italian).

Moretti, M., et al. (2012). Rapid response to the earthquake emergency of May 2012 in the Po Plain, northern Italy, Annals of Geophysics, 55 (4); doi:10.4401/ag-6152.

Peterson, J. (1993). Observations and modelling of background seismic noise, U.S. Geological Survey Open File Rep., 93-322.

Spallarossa, D., G. Ferretti, D. Scafidi and M. Pasta (2011). Picking automatico nella rete sismica dell'Italia nordoccidentale (RSNI), In: M. Cattaneo and M. Moretti (eds.), Monitoraggio sismico del territorio nazionale: stato dell'arte e sviluppo delle reti di monitoraggio sismico, Miscellanea INGV, 10, 141-146. ISSN 2039-6651 (in Italian).

Spallarossa, D., L. Tiberi and G. Costa (2012). Comparison of manual and automatic onset time picking for local earthquake in north-eastern Italy, EGU General Assembly, April 22-27, Vienna.

Thurber, C.H. (1983). Earthquake locations and three-dimensional crustal structure in the Coyote Lake area, central California, J. Geophys. Res., 88, 8226-8236.

Thurber, C.H. (1993). Local earthquake tomography: velocities and Vp/Vs - theory, In: H.M. Iyer and K. Hirahara (eds.), Seismic Tomography: Theory and Practice, Chapman \& Hall, 842 pp.

\footnotetext{
*Corresponding author: Simona Carannante, Istituto Nazionale di Geofisica e Vulcanologia, Centro Nazionale Terremoti, Ancona, Italy; email: simona.carannante@ingv.it. 